\title{
Socialstyrelsen, dronten och den evidensbaserade praktiken
}

\section{ANDERS BERGMARK \& TOMMY LUNDSTRÖM}

För några år sedan skrev undertecknade en artikel om evidensbaserat socialt arbete i Socialvetenskaplig tidskrift (Bergmark \& Lundström 2006). Artikeln följdes av en debatt mellan oss och en representant för dåvarande IMS (en organisation som numera är helt integrerad i Socialstyrelsen) (Anttila 2007a, b; Bergmark \& Lundström 2007a, b). En av de frågor som vi förgäves försökte få svar på i den debatten var hur IMS såg på den så kalllade "Drontens dom" eller på engelska "the Dodo bird verdict".

Fyra år senare tycks vårt önskemål ha hörsammats genom att Socialstyrelsen givit tre författare - Edward Mullen, Columbia University, Joseph Shuluk, Social Work Leadership Institute of the New York Academy of Medicine och Haluk Soydan, University of Southern California och Socialstyrelsen - i uppdrag att reda ut "Drontens dom". Det gör de i en skrift som heter

Anders Bergmark, professor i socialt arbete vid Stockholms universitet.

Tommy Lundström, professor i socialt arbete vid Stockholms universitet.
"Debatten om Dodo-fågeln: Spelar behandlingsmetoden någon roll i klientarbete?" (Socialstyrelsen 2011, publicerad på socialstyrelsens hemsida). Titeln på arbetet är i sig ett missförstånd. "Dodo-bird" på engelska är liktydigt med "dront" på svenska, begreppet dodo-fågel är i denna mening författarnas egen konstruktion. De tror dessutom att dronten är en fantasifågel, så är det inte; den fanns på Mauritius till dess den utrotades i mitten av 1600-talet. Det är naturligtvis petitesser i sammanhanget, men vad är då "Drontens dom"?

Uttrycket är hämtat från Lewis Carrolls "Alice i underlandet" där en dront, som agerar domare i förvirrad tävling, fastslår att "Alla har vunnit och alla måste få pris" (Carroll 1920, s. 34, vår översättning). Inom psykoterapiforskning har Drontens dom ända sedan 1930-talet kommit att beteckna frånvaron av skillnader i behandlingseffekt för väletablerade (bone fide) behandlingsinterventioner. Dronten har alltså dömt oavgjort mellan väletablerade psykoterapeutiska metoder och menar att de alla har positiv effekt (fenomenet betecknas också ställvis som "the outcome equivalence paradox'). 
Vi ser det som en i hög grad viktig fråga att diskutera vad Drontens dom, om den är riktig, kan ha för betydelse för synen på metoder i socialt arbete och vad det i så fall innebär i förhållande till evidensbaserad praktik (EBP). Delar av socialt arbete liknar psykoterapi och rimligtvis bör det vara av stor strategisk betydelse både för utbildningen i socialt arbete och för dess praktik om forskningen visar att dronten har rätt. De författare som Socialstyrelsen anlitat ser annorlunda på saken. De menar att saken redan är avgjord och att "Dodofågelhypotesen bygger på ett antal misstag i den vetenskapliga forskningsprocessen och att det idag finns ett omfattande vetenskapligt stöd för att olika behandlingsmetoder har differentierade/specifika effekter" (Socialstyrelsen 2011).

Till skillnad från Socialstyrelsens författare har förespråkare för Drontens dom i ökad utsträckning intresserat sig för vilka gemensamma egenskaper eller faktorer som utmärker god psykoterapi ${ }^{1}$. Den ackumulerade forskningen som pekar på att dronten har rätt framstår som såväl rationell som grundad på ett omfattande empiriskt underlag (i stor utsträckning kontrollerade experiment) och har över tid följts av liknande observationer på områden utanför psykoterapi (som studier av missbruksbehandling). Sammantaget pekar denna forskning mot en betydande nedtoning av nödvändigheten av metodtrogenhet som, när det gäller debatten om evidensbaserad

1 Så som en positiv behandlingsallians, motivation, patientens och terapeutens tilltro till behandlingen osv., se Wampold (2001) för en översikt. praktik, ofta kommer till uttryck i långtgående krav på en manualbasering av de interventioner som skall användas.

\section{"The great psychotherapy debate"}

Drontens dom har under de senaste tre decennierna utgjort epicentrum för en omfattande vetenskaplig kontrovers inom psykoterapiforskningen, men har sammantaget, menar vi, fått allt starkare stöd i vetenskaplig forskning också utanför psykoterapiområdet. På den ena sidan i denna kontrovers återfinns förespråkare av en medicinsk modell och på den andra anhängare av en kontextuell modell. De förra hävdar, som Socialstyrelsens författare, att vissa psykoterapier är mer effektiva än andra och att detta har sin grund $i$ att de innefattar specifika och särskilt effektiva inslag.

Den kontextuella modellens förespråkare understryker betydelsen av gemensamma faktorer (common factors, dvs. faktorer som finns närvarande i alla psykoterapier som är bona fide, som t.ex. "terapeutisk allians") och betraktar frånvaron av skillnader i utfall som en följd av de gemensamma faktorernas påtagliga dominans över mycket svaga eller helt frånvarande specifika inslag. Bruce Wampold (2001) har i sin uppmärksammade bok "The Great Psychotherapy Debate" analyserat en omfattande serie metaanalyser avseende de sista 30 årens forskning kring utfallet av olika typer av psykoterapier. Wampolds argumentation utgör ett mycket starkt argument till fördel för den kontex-

Anders Bergmark \& Tommy Lundström: Socialstyrelsen, dronten och den... 
tuella modellen och ett likaledes tungt vägande invändning visavi den medicinska. Den utan tvivel viktigaste metodologiska distinktionen i Wampolds analys utgörs av skillnaden mellan absolut och relativ effekt. Under det att absolut effekt erhålls via att jämföra en given behandlingsinterventions effekt på en experimentgrupp med en kontrollgrupp som inte erhåller någon behandlingsintervention (utan sätts upp på väntelista eller endast får del av en kontrollåtgärd som inte syftar att generera en behandlingseffekt), kräver identifieringen av en relativ effekt en jämförelse mellan två (eller flera) behandlingsinterventioner avsedda att ge behandlingseffekter (bona fide). Endast på så sätt kan man visa att den ena behandlingen är bättre än andra. Denna distinktion är utomordentligt betydelsefull eftersom det visat sig mycket svårt att påvisa att olika typer av psykosociala interventioner som kan karakteriseras som bona fide ger skillnader i utfall, medan det varit relativt lätt att visa på att psykoterapeutiska interventioner som sådana, har effekt.

Märkligt nog har Socialstyrelsens författare valt att helt ignorera Wampolds forskning i sitt avfärdande av Drontens dom. Det framstår som anmärkningsvärt med tanke på tyngden i hans argumentation och hur ofta han annars citeras. Detta förbiseende bäddar också för författarnas höggradigt kontroversiella ståndpunkt att: "Numera visar den samlade, kvalificerade forskningen om differentierande behandlingseffekter att Dodofågelhypotesen i princip saknar vetenskapligt stöd" (Socialstyrelsen 2011 , s.11). Det torde vara få forskare inom psykoterapiområdet, såväl i Sverige som internationellt som inte tillstår att Drontens dom utgör en del av en central och alltjämt levande vetenskaplig diskussion (se t.ex. Armelius 2005; Norcross, Beutler \& Levant 2006).

De sju argument som författarna anför som skäl att avvisa Drontens dom har alla vederlagts i Wampolds empiriska analyser. Författarna tycks vidare inte ha uppmärksammat att den studie som de själva tilldelar störst tyngd i den egna rapporten (Reid et al. 2004) tydligt identifierar och stödjer realiteten hos Drontens dom, så här skriver Reid och hans kollegor:

Research reviews and meta-analyses of these experiments have consistently failed to find much evidence of differential effects (Ahn \& Wampold, 2001; Gloaguen, Cottraux, Cucherat, \& Blackburn, 1998; Luborsky et al. 1999; Luborsky, Singer, \& Luborsky, 1975; Shapiro \& Shapiro, 1982; Smith, Glass, \& Miller, 1980; Wampold et al., 1997). Some comparative experiments have produced differential effects, mainly in treatment of children and adolescents (Chambless \& Ollendick, 2001), "but they are the exception rather than the rule" (s. 72, vår kursivering). ${ }^{2}$

Det Reid och hans kollegor ifrågasätter, är således inte giltigheten hos Drontens dom inom psykoterapiområdet, de sätter frågetecken inför huruvida Drontens dom också är giltig för de interventioner som är aktuella inom socialt arbete. Det är naturligtvis en berättigad fråga.

2 För tillgång till de $\mathrm{i}$ citatet ingående referenserna se Reid et al. (2004). 


\section{Drontens dom och socialt arbete}

En mer närgången granskning av det material som bildar grunden för den analys som förs fram av Reid, Kenaley, \& Colvin, J. (2004) om differentiella effekter av det sociala arbetets insatser avslöjar dock betydande brister i detsamma. Av de 39 studier som selekterats till analysen innefattar endast en minoritet också en i tid förskjuten uppföljning efter det att interventionen har avslutats, i 27 av studierna jämförs effekterna av de olika interventionerna endast i samband med att de avslutas (dvs. utan någon uppföljning över tid). Frånvaron av uppföljningstid (eller allt för kort uppföljning) utgör en kvalitetsbrist som i normalfallet leder till att studier av denna typ inte inkluderas i en analys av effekter (detta gäller t.ex. vid analyser genomförda av SBU). Om dessa 27 analyser tas bort återstår 12 studier med någorlunda rimliga uppföljningstider, 7 av dessa uppvisar skillnader mellan de ingående interventionerna under det att de resterande 5 inte uppvisar några skillnader. Gruppen med identifierade skillnader hade dock en påtagligt större andel studier av lägre kvalitet (kvasiexperimentell design, 5 av 7) jämfört med den grupp som inte identifierade några skillnader (1 av 5 hade en kvasiexperimentell design). Sammantaget ger detta för handen att såväl Reid et al. (2004) som författarna till Socialstyrelsens rapport har dragit allt för långtgående växlar på ett material vilket måste betraktas som påtagligt svagt.

Socialstyrelsens ambition att via beställningen och publiceringen av den aktuella rapporten kullkasta giltigheten hos Dron- tens dom tycks i allt väsentligt ha skett i en fullständig omedvetenhet om att den egna myndigheten i andra sammanhang understödjer Drontens ställningstagande. Den reviderade engelska versionen av Statens beredning för medicinsk utvärdering (SBU, Berglund et al. 2003) översikt beträffande interventioner för alkohol- och drogmissbruk utgör ett av de mest centrala dokumenten för de nationella riktlinjer för missbruks- och beroendevård som Socialstyrelsen publicerade 2007. Resultaten avseende effekterna av behandlingsinterventioner för alkoholproblem i SBU:s översikt sammanfattas i ett antal slutsatser av vilka de mest centrala är följande:

\section{"Behandling är effektiv.}

Specifik behandling är bättre än standardbehandling.

Ingen specifik behandling är överlägsen någon annan.

Stödet för matchning med en specifik behandlingsmetod är svagt."

(Berglund et al. 2003, s. 87-88, vår översättning).

I allt väsentligt är dessa slutsatser av den arten att de skulle kunna komma direkt från Drontens näbb, det vill säga att det i det allmänna fallet inte tycks föreligga några skillnader i utfall mellan psykosociala behandlingsinterventioner för alkoholmissbruk som är utformade för att vara reella interventioner (bona fide). Berglund et al. (2003) använder termen "specifik behandling" för behandlingsinterventioner som har ett teoretiskt fundament och som iscensätts via manualer och utbildade terapeuter.

Anders Bergmark \& Tommy Lundström: Socialstyrelsen, dronten och den... 


\section{Missbruksbehandling}

Det är betecknande att författarna inte med ett ord berör utvecklingen inom missbruksområdet där de senaste 10 åren har medfört ett allt tydligare släktskap med psykoterapiområdets frånvaro av skillnader i utfall mellan olika typer av behandlingsinterventioner. Den monumentala studien "Project MATCH" designades för att kunna belysa huruvida en matchning kunde förbättra utfallet för olika typer av behandlingsinterventioner. Detta iscensattes i två parallella studier, en öppenvårdsstudie och en eftervårdsstudie. Tre olika typer av behandlingsinterventioner, "kognitiv beteendeterapi" (CBT), "motivationsförstärkande terapi" (MET) och 12-stegs förstärkande terapi (TSF) studerades i båda delstudierna.

Projektets syfte och design krävde behandlingsalternativ som tydligt skiljde sig åt både vad gäller teoretiska fundament och genomförande. Av detta skäl lades stor vikt vid att välja behandlingsalternativ som sinsemellan karakteriserades av distinkta skillnader och att implementeringen av de olika behandlingsinterventionerna genomfördes via detaljerade manualer. Trots det extensiva teoretiska underlaget och att såväl design som genomförande kännetecknades av en utomordentlig metodologisk kvalitet, identifierade Project MATCH i princip inga robusta och tolkningsbara matchningseffekter. Utöver detta visade sig också utfallet för de tre olika behandlingsinterventionerna, utan hänsyn till huruvida individerna var rätt eller fel matchade, i princip vara likartat. Project MATCH kan därmed betraktas som en studie som utgör ett mycket starkt empiriskt stöd för giltigheten hos Drontens dom.

The UK Alcohol Treatment Trial (UKATT) initierades i början av 2000-talet och utgör den mest omfattande studien av psykosociala behandlingsinterventioner som någonsin har genomförts i Storbritannien. UKATT genomfördes som en randomiserad kontrollerad studie (RCT) vid fem olika behandlingscentra. Studien innefattade knappt 750 individer som antingen erhöll "motivationsförstärkande terapi" (MET, vilken var avsedd att fungera som kontrollintervention) eller "social beteende- och nätverksterapi" (SBNT, avsedd att utgöra experimentinterventionen). Vid uppföljningen 12 månader efter avslutad behandling kunde inga skillnader identifieras i utfall mellan de båda behandlingsgrupperna (UKATT research team, 2005). I efterhand undersöktes huruvida en analys av fem riktade matchningshypoteser kunde identifiera några skillnader i utfall för de individer som erhållit en matchning enligt någon av de fem hypoteserna. Ingen av de fem matchningshypoteserna bekräftades vid analysen av utfallet efter 12 månader (UKATT research team 2007). Resultaten från UKATT-studien uppvisar en mer eller mindre fullständig parallellitet med resultaten från Project MATCH och utgör därmed ytterligare stöd för giltigheten hos Drontens dom.

\section{Multisystemisk terapi}

Förutom Reid et al. (2001) hänvisar rapportförfattarna till andra evidensprodu- 
center: "Moderna kunskapsportaler (eng. clearinghouse) för evidensbaserade interventioner beskriver ofta interventioner som har olika starka effekter. Exempelvis tillhandahåller The California EvidenceBased Clearinghouse for Child Welfare (www.cebc4cw.org) för närvarande 23 effektiva interventioner med starkt vetenskapligt stöd och differentiella effekter inom barn och ungdomsområden" (Socialstyrelsen 2011, s. 12). Tittar man närmare på $\mathrm{CEBC}$ lista över verksamma interventioner, blir man emellertid en smula undrande. Där ges till exempel Multisystemisk terapi högsta betyg (Scientific Rating of 1 - Well-Supported by Research Evidence), men studier finansierade och publicerade av Socialstyrelsen själva visar att MST knappast har någon positiv effekt jämfört med ordinarie behandling (Sundell et al. 2006, 2008; Littell et al. 2005). Ett skäl till att CEBS hamnar där de gör är att de väljer att inte redovisa de viktigaste studierna som pekar på noll-resultat i sitt vetenskapliga underlag. Också för andra interventioner där CEBC anger "well-supported by Research Evidence" är evidensläget i själva verket oklart eller motsägelsefullt.

\section{Skadliga effekter}

Avslutningsvis några ord om skadliga effekter. Här har författarna en poäng. I socialt arbete liksom i andra människobehandlande professioner måste man som de pekar på undvika verksamheter som kan vara skadliga. Men sen går det fel i deras argumentation. Rapportförfattarna skriver:
"Eftersom det finns skadliga insatser (t.ex. Scared Straight) betyder det att det finns skillnader som inte endast beror på generella faktorer" (Socialstyrelsen 2011, s. 14). Det mesta pekar helt riktigt på att Scared Straight - en uppsättning interventioner som baseras på att ungdomar får träffa kriminella i fängelse och därmed skall skrämmas från att själva begå brott - i själva verket leder till att de begår fler brott. Det är emellertid långt ifrån klart att det har med specifika komponenter att göra. Frågan är för det första om man alls bör betrakta Scared Straight som en behandlingsintervention. Scared Straight utförs inte på basis av ett sammanhållet enhetligt program eller utifrån en elaborerad teoribildning. Det är, för det andra, troligt att Scared Straight i de flesta fall genomförs i grupp (det är inte alldeles lätt att förstå av forskningssammanställningarna), Gruppbehandling är en generell/kontextuell faktor, med känd negativ inverkan på utfall när det gäller stökiga ungdomar (Dodge, Dishion \& Lansford 2006; Petrosino, Turpin-Petrosino \& Buehler 2002). Forskning som påvisat skadliga effekter på ungdomsområdet motsäger således inte Drontens dom.

\section{Avslutande anmärkningar}

Den nyfikenhet som vi uttryckte 2006 har delvis blivit stillad. Vi har fått reda på mer om hur Socialstyrelsen, genom de författare de gett i uppdrag att reda ut saken, ser på Drontens Dom. Det är naturligtvis bra, men samtidigt reser sig nya och lite bekymmersamma frågor. Den viktigaste handlar kanske om rapportens tvärsäkra

Anders Bergmark \& Tommy Lundström: Socialstyrelsen, dronten och den... 
hållning. Det finns inget utrymme för tvivel hos författarna: Drontens Dom är felaktig. I den här artikeln har vi visat att det knappast är en trovärdig slutsats. Mycket talar för att Wampold och andra anhängare av en kontextuell modell faktiskt i det stora hela har rätt och att de senaste årens forskning, framförallt på missbruksområdet, snarast stärkt deras position.

Det som för oss framstår som märkligt är att en svensk statlig myndighet så klart väljer att ta ställning i en vetenskaplig kontrovers där de flesta forskare, även om de inte instämmer med Wampold i alla detaljer, ändå menar att frågorna är värda att ta på allvar. De kan knappast avfärdas så enkelt som det görs i rapporten. Socialstyrelsens ställningstagande tycks oss med andra ord för grovt och förenklat och därför faktiskt en smula bekymmersamt. Man kan fråga sig varför detta arbete beställts och vilken position det har i myndigheten. Är det ett diskussionsinlägg borde det framgått av förordet och är det Socialstyrelsens ståndpunkt borde det och konsekvenser därav tydliggöras.

\section{Referenser}

Anttila, S. (2007a). Svar på replik från Bergmark och Lundström. Socialvetenskaplig tidskrift, 4, 312-316.

Anttila, S. (2007b). Slutord. Socialvetenskaplig tidskrift, 4, 322-323.

Armelius, Å. (2005). Psykoterapi. I Hwang, P. et al. (red.) Var tids psykologi. Stockholm: Natur \& Kultur.

Berglund, M., Thelander, S. \& Jonsson, E. (red.) (2003). Treating alcohol and drug abuse: an evidence based review. Viernheim: Wiley-VCH.

Bergmark, A. \& Lundström, T. (2006). Mot en evidensbaserad praktik? Om färdriktningen i socialt arbete. Socialvetenskaplig tidskrift, 2, 99-113.

Bergmark, A. \& Lundström, T. (2007a). Om metaanalyser som styrmedel i socialt arbetet. Socialvetenskaplig tidskrift, 4, 317-321.

Bergmark, A. \& Lundström, T. (2007b). Kartan och terrängen. Om evidensbaserad praktik (EBP) som ideal och verklighet. Socialvetenskaplig tidskrift, 1,77-82.
Carroll, L. (1920). Alice's Adventures in Wonderland. New York: McMillan.

Dodge, K., Dishion, T. \& Lansford, J. (red.) (2006). Deviant peer influences in programs for youth. New York: Guilford.

Littell J., Popa, M. \& Forsythe, B. (2005). Multisystemic therapy for social, emotional, and behavioral problems in youth aged 10-17.Campbell Systematic Reviews, 2005:1.

Norcross, J., Beutler, L. \& Levant R. (2006). Evidence-based Practices in Mental Health: Debate and dialogue on the fundamental questions. Washington, DC: American Psychological Association.

Petrosino, A. Turpin-Petrosino C., \& Buehler J. (2002). "Scared straight" and other juvenile awareness programs for preventing juvenile delinquency. Cochrane Database of Systematic Reviews 2002, Issue 2.

Reid, WJ., Kenaley, BD., \& Colvin, J. (2004). Do some interventions work better than others? A review of comparative social work experi- 
ments. Social Work Research. 28, 71-81.

Socialstyrelsen (2011). Debatten om Dodo-fägeln: Spelar behandlingsmetoden någon roll $i$ klientarbete? Stockholm: Socialstyrelsen.

Sundell K., Hansson, K., Andrée Löfholm, C., Olsson, T., Gustle, L. \& Kadesjö, C. (2006). Multisystemisk terapi för ungdomar med allvarliga beteendeproblem: resultat efter sex månader[en rapport från IMS]. Stockholm: Institutet för utveckling av metoder i socialt arbete (IMS).
Sundell, K. Hansson, K., Andrée Löfholm, C., Olsson, T.; Gustle, L. Kadesjö, C. (2008). Transportability of multisystemic therapy to Sweden: short-term results from a randomized trial of conduct-disordered youths. Journal of Family Psychology, 22, 550-560.

Wampold, B. (2001). The great psychotherapy debate - models, methods and findings. New Jersey: Lawrence Erlbaum Associates.

Anders Bergmark \& Tommy Lundström: Socialstyrelsen, dronten och den... 